\title{
Xác định các chất nhóm macrolide và tetracycline trong nước bằng phướng pháp sắc kỷ lởng hai lần khối phổ (LC-MS/MS)
}

\author{
Lê Văn Trọng ${ }^{1,2^{*}}$, Nguyễn Thị Thanh Hằng${ }^{1}$, Đỗ Quang Huy ${ }^{2}$, Nguyễn Mạnh Khải ${ }^{2}$ \\ ${ }^{1}$ Trung tâm Phân tích và Giám định thực phẩm Quốc gia, Viện Công nghiệp thực phẩm \\ ${ }^{2}$ Khoa môi trường, Trường Đại học Khoa học tự nhiên, Đại học Quốc gia Hà Nội
}

(Ngày đến tòa soạn: 21/7/2020; Ngày chấp nhận đăng: 18/9/2020)

\section{Tóm tắt}

Kháng sinh là chất có thể gây ô nhiễm ở nồng độ thấp và được thấy trong môi trường nước ở khoảng nồng độ ng/L. Việc xác định các chất có hàm lượng vết đòi hỏi trang thiết bị hiện đại và độ chính xác cao. Phương pháp sắc ký lỏng hai lần khối phổ (LC-MS/MS) với khả năng xác định các chất ở nồng độ ppt và ppb phù hợp để định lượng các chất nhóm macrolide và tetracycline trong nước. Phương pháp phân tích sử dụng hệ thống Agilent Triple Quard 6460 LC-MS/MS với nguôn phun ion hóa điện tử chế độ ion dương, cột phân tích Agilent XDB C18 $(1,8 \mu \mathrm{m} \times 2,1 \times 100 \mathrm{~mm})$ và tiền cột Agilent Eclipse SDB C18 $(2,1 \times 5 \mathrm{~mm} \times 1,8 \mu \mathrm{m})$. Dung môi pha động acetonitrile và $\mathrm{HCOOH} 0,1 \%$. Làm sạch mẫu bằng cột chiết pha rắn Oasis $\mathrm{PRiME}$ HLB 3cc (150 mg). Phương pháp được đánh giá dựa trên độ đặc hiệu, độ thu hôi, độ lặp lại và ước lượng độ không đảm bảo đo. Giới hạn phát hiện (LOD) của phương pháp đối với các chất phân tích là $0,03 \mu \mathrm{g} / \mathrm{L}$. Độ thu hồi nằm trong khoảng 85,23\% đến $117,70 \%$; độ lặp lại $\left(\mathrm{RSD}_{\mathrm{r}}\right)$ nằm trong khoảng 2,20 - 12,45\%.

Tư khóa: kháng sinh, macrolides, tetracyclines, LC-MS/MS.

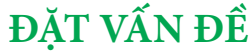

Kháng sinh lần đầu tiên được phát hiện vào năm 1928 sau đó được sử dụng rộng rãi trong $\mathrm{y}$ học để chữa bệnh cho người và động vật. Các con đường kháng sinh đi vào môi trường nước rất đa dạng bao gồm nước thải và dòng chảy rửa trôi từ đất do nguôn sử dụng phân bón cho nông nghiệp hoặc chất thải của con người [1]. Thuốc kháng sinh được sử dụng rộng rãi để điều trị các bệnh truyền nhiễm. Tuy nhiên 30 - 90\% kháng sinh được bài tiết dưới dạng hợp chất gốc hoặc chuyển hóa trong nước tiểu và phân vào môi trường [2]. Theo Bộ Nông nghiệp và Phát triển Nông thôn, một loạt các kháng sinh được sử dụng hợp pháp trong chăn nuôi trong đó có hơn 30 loại kháng sinh thuộc nhóm sulfonamide, beta lactam, quinolone, macrolide, cyclines và một số loại kháng sinh khác được sử dụng hạn chế [3]. Một số loại kháng sinh phổ rộng bị cấm trong nuôi trồng thủy sản như chloramphenicol, nitroimidazole và hầu hết các chất nhóm fluoroquinolone. Các trang trại nuôi cá sử dụng phổ biến nhất là enrofloxacin (quinolones) (69\%), florphenicol (amphenicols) (63\%), sulfamethoxazole (sulfonamide) kết hợp với trimethoprim (44\%), doxycyclines (cyclines) (34\%) [4].

Vì kháng sinh là những hợp chất có thể tiêu diệt hoặc ức chế sự phát triển của vi sinh vật nên chúng có khả năng làm mất sự cân bằng của hệ sinh thái. Theo Kummerer và cộng sự (2009) [5] dư lượng kháng sinh trong môi trường có thể gây kháng thuốc cho vi sinh vật ở nồng 
độ thấp, sau đó gen kháng kháng sinh có thể chuyển sang con người hoặc động vật theo chuỗi và lưới thức ăn. Theo nghiên cứu nhiều loại kháng sinh như amoxicillin, benzyl penicillin, sarafloxacin, spiramycin, tetracycline và tiamulin ức chế sự phát triển của tảo lam. Theo một nghiên cứu của Le và cộng sự (2005) [6] vi khuẩn kháng kháng sinh norlfoxacin được tìm thấy ở bùn và mẫu nước cạnh trang trại nuôi tôm ở nông độ $0,1 \mu \mathrm{g} / \mathrm{mL}$. Theo nghiên cứu Kim và cộng sự (2007) [7], sulfamathoxazole, sulphachlorpyridazine, sulfathiazole, sulphamethazine, sulphadimethoxine và trimethoprim gây độc cấp tính cho thủy sản gồm vi khuẩn biển (Vibrio fischeri), động vật không xương sống nước ngọt (Daphnia magna), và cá medaka Nhật Bản (Oryzias latipes) với giá trị nông độ môi trường dự đoán (PEC) dao động từ 0,14 - 16,5 $\mu \mathrm{g} / \mathrm{L}$.

Macrolide là một nhóm thuốc kháng sinh đã được sử dụng để điều trị nhiều bệnh nhiễm trùng đường hô hấp và đường ruột ở người và động vật. Một số macrolide được sử dụng phổ biến là spiramycin (SPI), erythromycin (ERY), tylosin (TYL), roxithromycin. Theo tác giả Fatta Kassinos (2011) [8], erythromycin được tìm thấy trong nước mặt ở khoảng 4,7 - 1900 ng/L, spiramycin trong khoảng 3,3 - 459,5 ng/L, tylosin $60 \mathrm{ng} / \mathrm{L}$.

Nhóm tetracycline là một họ kháng sinh phổ rộng bao gồm tetracycline (TC), oxytetracycline (OTC), chlortetracycline (CTC), doxycycline (DOC) và minocycline [1], nhóm kháng sinh này ức chế sự tổng hợp của vi khuẩn gram dương và gram âm. Nhóm tetracycline được sử dụng trong điều trị một sô bệnh về da và răng ở người. Ngoài ra, nhóm tetracycline còn được sử dụng rộng rãi trong nông nghiệp như là chất kích thích tăng trưởng trong trang trại chăn nuôi và làm thuốc dự phòng trong nông nghiệp và nuôi trông thủy sản. Theo tác giả Lin và cộng sự (2008) [9], tetracycline được tìm thấy trong nước thải công nghiệp ở nồng độ $1,5 \times 10^{3}$ $\mathrm{ng} / \mathrm{L}$, oxytetracycline $1,5 \times 10^{4} \mathrm{ng} / \mathrm{L}$.

Do gây ô nhiễm ở nông độ thấp và thường xuất hiện trong môi trường nước ở nồng độ ng/L. Việc xác định các chất kháng sinh đòi hỏi thiết bị phân tích hiện đại với độ chính xác cao. Phương pháp sắc ký lỏng hiệu năng cao kết hợp đầu dò hai lần khối phổ là phương pháp phù hợp được chọn để phân tích các hợp chất này trong môi trường nước. Nghiên cứu này nhằm xác định hàm lượng các chất nhóm macrolide và tetracycline trong nước, công thức cấu tạo của các chất nghiên cứu được thể hiện trong Hình 1.

Erythromycin

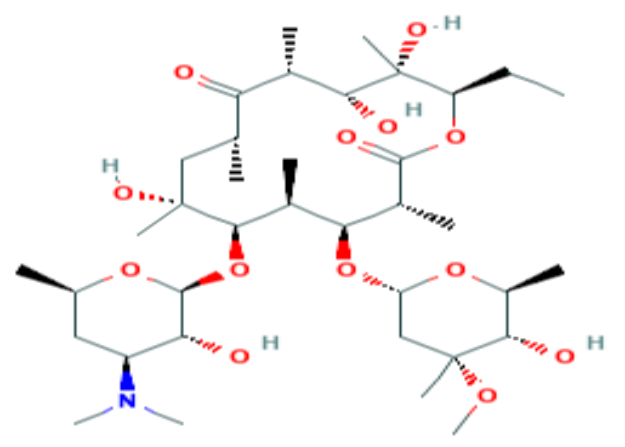

Tetracycline

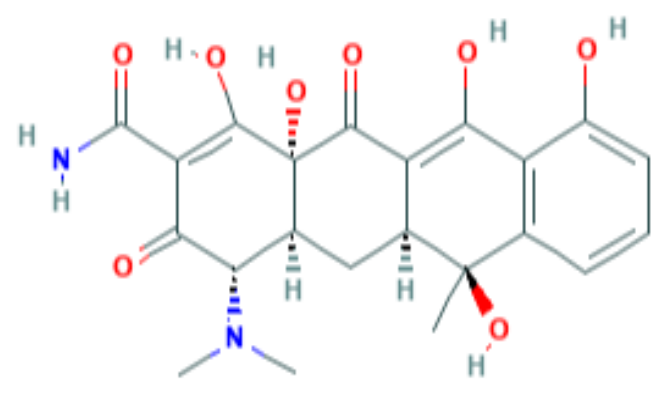



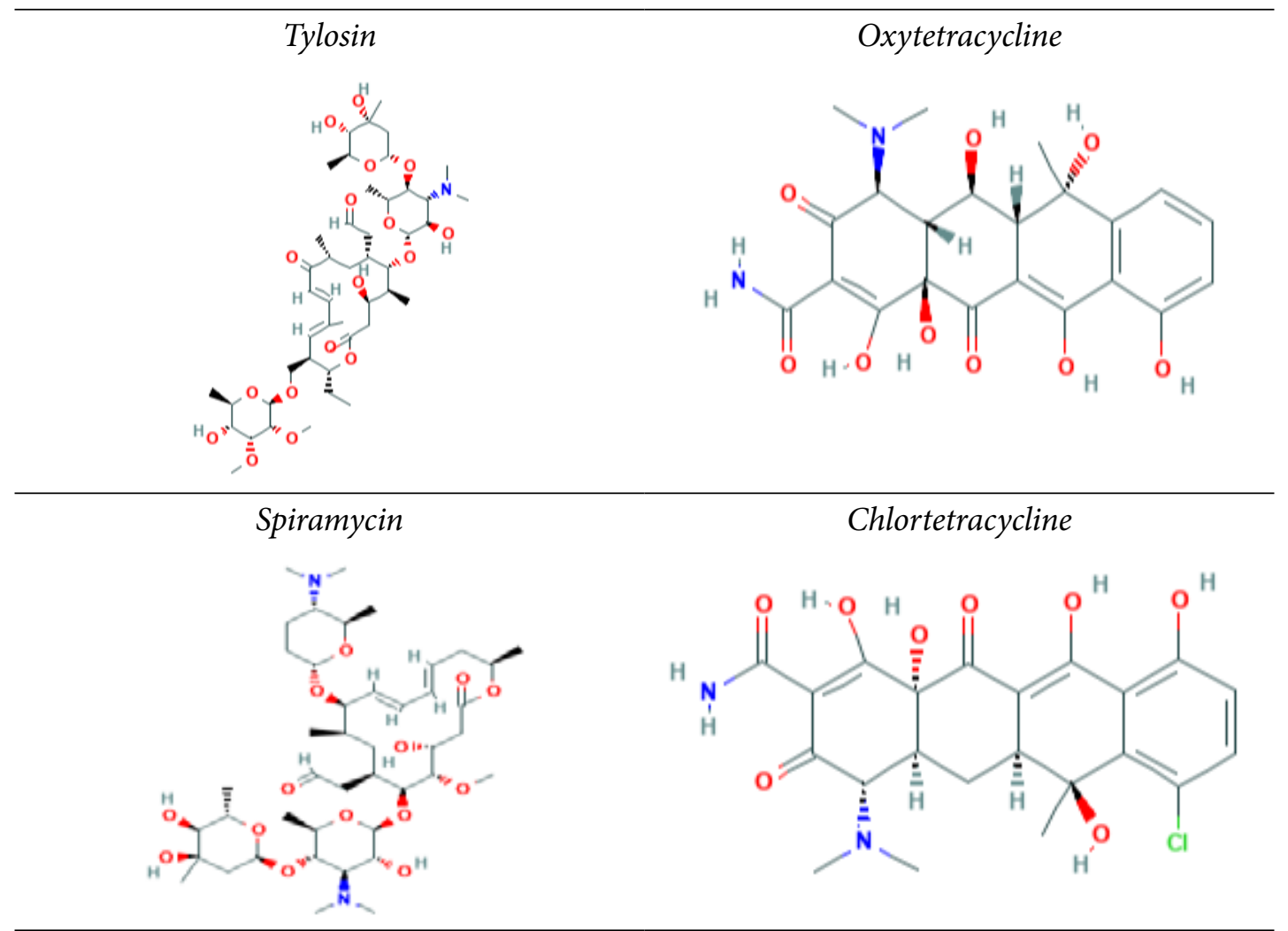

Hình 1. Công thức cấu tạo các chất nhóm MAC và TCs

\section{VẠT LIỆU VÀ PHƯƠNG PHÁP NGHIÊN CƯU}

\subsection{Hóa chất}

Tất cả hóa chất sử dụng đều là tinh khiết, đạt chuẩn để phân tích HPLC và nước deion, methanol, acid fomic. Chuẩn dạng bột tetracycline hydrochloride (96,8\%), oxytetracycline hydrochloride (90,9\%), chlotetracycline hydrochloride (93,7\%), spiramycin (92,6\%), erythromycin (99,0\%) được cung cấp bởi Sigma, tylosin tatrate $(99,0 \%)$ được cung cấp bởi Dr. Ehrenstorfer. Dung dịch chuẩn gốc được pha trong $\mathrm{MeOH}$ ở nồng độ $1.000 \mu \mathrm{g} / \mathrm{mL}$ bảo quản ở $-20^{\circ} \mathrm{C}$. Chuẩn làm việc được pha từ chuẩn gốc trong nước deion.

\subsection{Thiết bị, dụng cụ}

Các thiết bị sử dụng cho phân tích các chất nhóm macrolide và tetracyclines gồm LC-MS/ MS của Agilent với 6460 Infinity LC và 6460 Triple Quadrupole với nguôn ESI. Cột sử dụng là cột Agilent XDB C18 $(1,8 \mu \mathrm{m} \times 2,1 \times 100 \mathrm{~mm})$ và tiên cột Agilent Eclipse SDB C18 $(2,1 \times 5 \mathrm{~mm}$ $\times 1,8 \mu \mathrm{m})$. Các thiết bị dụng cụ khác bao gồm cột chiết pha rắn Oasis PRiME HLB 3cc $(150 \mathrm{mg})$, bộ chiết pha rắn Supelco kèm máy hút chân không, máy lắc vortex và các dụng cụ thí nghiệm khác.

\subsection{Chuẩn bi mẫu}

Các mẫu thử được tạo bằng cách thêm chuẩn vào nền mẫu trắng ở các nồng độ thêm chuẩn khác nhau. Sau đó mẫu được chuẩn bị để phân tích theo các bước như sau: $100 \mathrm{~mL}$ nước thải được chỉnh $\mathrm{pH}$ đến 4,5 bằng acid fomic. Lọc qua giấy lọc. Dịch lọc được làm sạch bằng cột chiết pha rắn SPE PRiME HLB $3 \mathrm{~mL}$. Hoạt hóa cột lần lượt bằng $3 \mathrm{~mL} \mathrm{MeOH,} 3 \mathrm{~mL}$ nước. 
Chuyển toàn bộ dịch lọc qua cột SPE, sau đó rửa giải bằng $3 \mathrm{~mL} \mathrm{MeOH}$. Dịch thu được thổi khô bằng khí Nitơ. Hòa tan cặn bằng $1 \mathrm{~mL} \mathrm{MeOH}$. Lọc mẫu qua màng $0,22 \mu \mathrm{m}$ vào lọ mẫu $1,5 \mathrm{~mL}$ và xác định bằng $\mathrm{LC}-\mathrm{MS} / \mathrm{MS}$.

\section{4. Điều kiện LC-MS/MS}

Các chất phân tích được xác định bằng phương pháp sắc ký lỏng, hai lần khối phổ. Điều kiện vận hành hệ thống được thể hiện trong Bảng 1 .

Bảng 1. Điều kiện phân tích các kháng sinh bằng LC-MS/MS

\begin{tabular}{|c|c|c|}
\hline & Nhóm Macrolide & Nhóm Tetracycline \\
\hline \multicolumn{3}{|l|}{ Điều kiện LC } \\
\hline Cột & $\begin{array}{c}\text { Agilent XDB - C18 } \\
(1,8 \mu \mathrm{m} \times 2,1 \times 100 \mathrm{~mm})\end{array}$ & $\begin{array}{c}\text { Agilent XDB - C18 } \\
(1,8 \mu \mathrm{m} \times 2,1 \times 100 \mathrm{~mm})\end{array}$ \\
\hline Tốc độ dòng (mL/phút) & 0,3 & 0,3 \\
\hline Pha động & $\begin{array}{c}\text { A: Acetonitrile } \\
\text { B: HCOOH 0,1\% }\end{array}$ & $\begin{array}{c}\text { A: Acetonitrile } \\
\text { B: HCOOH 0,1\% }\end{array}$ \\
\hline Gradient & $\begin{array}{c}0 \text { - } 6 \text { phút: } 20 \% \mathrm{~A} \\
6 \text { phút: } 60 \% \mathrm{~A} \\
6,01-7 \text { phút: } 20 \% \mathrm{~A}\end{array}$ & $\begin{array}{c}0 \text { - } 5 \text { phút: } 10 \% \mathrm{~A} \\
5 \text { phút: } 30 \% \mathrm{~A} \\
\text { 5,01- } 6: 70 \% \mathrm{~A} \\
6,01-7 \text { phút: } 10 \% \mathrm{~A}\end{array}$ \\
\hline Thời gian phân tích (phút) & 7 & 7 \\
\hline Thời gian dừng (phút) & 2 & 2 \\
\hline Nhiệt độ cột ( $\left.{ }^{\circ} \mathrm{C}\right)$ & 25 & 25 \\
\hline Thể tích bơm $(\mu \mathrm{L})$ & 5 & 5 \\
\hline \multicolumn{3}{|l|}{ Điều kiện khối phổ } \\
\hline Nguồn ion hóa & ESI & ESI \\
\hline Chế độ ion hóa mẫu & Positive & Positive \\
\hline Nhiệt độ khí $\mathrm{N}_{2}\left({ }^{\circ} \mathrm{C}\right)$ & 300 & 350 \\
\hline Tốc độ khí $\mathrm{N}_{2}$ (1/phút) & 8 & 10 \\
\hline Nhiệt độ cột $\left({ }^{\circ} \mathrm{C}\right)$ & 25 & 25 \\
\hline Áp suất bay hơi dung môi (psi) & 45 & 45 \\
\hline Điện áp mao quản (V) & 2.000 & 2.000 \\
\hline
\end{tabular}

\section{5. Ước lượng độ không đảm bảo đo}

Độ không đảm bảo đo của phép đo đặc trưng cho độ phân tán của các giá trị có thể chấp nhận được quy cho đại lượng của phép đo. Độ không đảm bảo đo nói lên độ tin cậy của phép đo.

Độ không đảm bảo đo u được tính theo công thức [10]:

$$
U(\%)=\sqrt{\frac{\Sigma\left(x_{i}-x_{t b}\right)^{2}}{n-1}} \times \frac{1}{x_{t b}}
$$


Trong đó:

u: độ không đảm bảo đo;

$\mathrm{x}_{\mathrm{i}}$ : giá trị thứ $\mathrm{i}$;

$\mathrm{x}_{\mathrm{tt}}$ : giá trị trung bình;

n: số lần làm lặp lại.

Độ không đảm bảo đo mở rộng U \% được tính theo công thức

$$
\begin{aligned}
& \mathrm{U}=\mathrm{k} \times \mathrm{U}_{\mathrm{TH}} \\
& \mathrm{U}_{\mathrm{TH}}=\sqrt{u_{a}^{2}+u_{b}^{2}}
\end{aligned}
$$

Trong đó: $\mathrm{k}$ là hệ số phủ được cho giá trị bằng 2 tương ứng với độ tin cậy $95 \%$; $\mathrm{u}_{\mathrm{a}}, \mathrm{u}_{\mathrm{b}}$ là độ không đảm bảo đo của chuẩn và của quá trình lặp lại.

\section{KẾT QUẢ VÀ BÀN LUÂN}

\section{1. Độ đặc hiệu của phương pháp}

Đối với kỹ thuật phân tích LC-MS/MS số điểm IP phải đạt được là 4 [10]. Thực hiện bắn phá 1 ion mẹ và thu được 2 ion con. Với 1 ion mẹ thu được 1 IP và mỗi ion con thu được $1,5 \mathrm{IP}$. Theo cách tính thu được 4 điểm IP, như vậy phương pháp có tính đặc hiệu đáp ứng được yêu câu. Thời gian lưu của từng chất phân tích được thể hiện trong Bảng 2.

Bảng 2. Chế độ phân tích $M R M$

\begin{tabular}{lccccc}
\hline Chất phân tích & Mảnh mẹ & Mảnh con & $\begin{array}{c}\text { Fragmentor } \\
(\boldsymbol{V})\end{array}$ & $\begin{array}{c}\text { Collision ener- } \\
\text { gy }(\text { V) }\end{array}$ & $\begin{array}{c}\text { Thòi gian luiu } \\
\text { (phút) }\end{array}$ \\
\hline Tetracycline & 445 & 427 & 120 & 15 & 3,361 \\
Tetracycline & 445 & $410^{*}$ & 120 & 20 & 3,361 \\
Oxytetracycline & 461 & 443 & 120 & 20 & 2,967 \\
Oxytetracycline & 461 & $426^{*}$ & 120 & 20 & 2,967 \\
Chlotetracycline & 479 & 462 & 120 & 15 & 4,726 \\
Chlotetracycline & 479 & $444^{*}$ & 120 & 22 & 4,726 \\
Tylosin & 916,5 & 772,4 & 119 & 30 & 3,769 \\
Tylosin & 916,5 & $174,1^{*}$ & 119 & 40 & 3,769 \\
Erythromycin & 734,5 & 576,4 & 124 & 14 & 3,477 \\
Erythromycin & 734,5 & $158,1^{*}$ & 124 & 26 & 3,477 \\
Spiramycin & 843,5 & 142,2 & 145 & 40 & 2,207 \\
Spiramycin & 843,5 & $174,2^{*}$ & 145 & 34 & 2,207 \\
\hline
\end{tabular}

Ghi chú: * mảnh định lượng

\subsection{Khoảng tuyến tính và giới hạn của phương pháp}

Đường ngoại chuẩn được xây dựng bởi 5 điểm chuẩn có hàm lượng lần lượt là 10;20;50; $100 ; 200 \mu \mathrm{g} / \mathrm{L}$ đối với các chất nhóm tetracylin và $5 ; 10 ; 50 ; 100 ; 200 \mu \mathrm{g} / \mathrm{L}$ đối với các chất nhóm macrolide. Kết quả thu được thể hiện trong Bảng 3 với hệ số tương quan $\mathrm{R}^{2}$ từ 0,9990 - 0,9999 
(Hình 1). Giá trị giới hạn phát hiện (LOD) của phương pháp được xác định dựa vào tỷ lệ tín hiệu trên nhiễu nền $\mathrm{S} / \mathrm{N}$ bằng cách thêm chuẩn vào nền mẫu trắng tại mức nồng độ $0,03 \mu \mathrm{g} / \mathrm{L}$. Tất cả $\mathrm{S} / \mathrm{N}$ đều lớn hơn $3: 1$. Do đó $\mathrm{LOD}$ của các chất phân tích được lấy là $0,03 \mu \mathrm{g} / \mathrm{L}$ và giới hạn định lượng LOQ là $0,10 \mu \mathrm{g} / \mathrm{L}$.
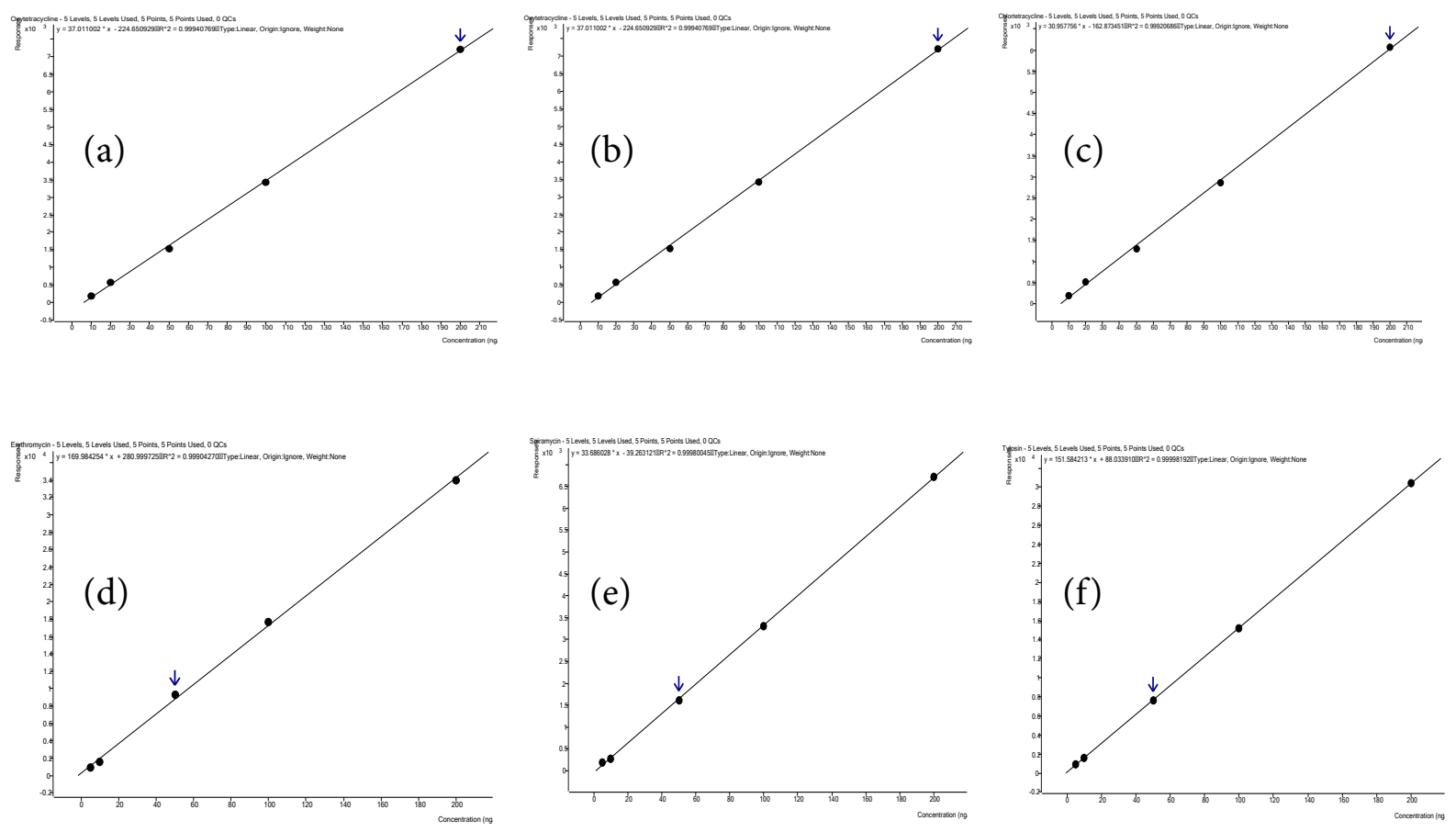

Hình 1. Đường chuẩn của các chất nhóm tetracyline và macrolide

$$
a \text { - OTC, } b \text { - TC, c - CTC, } d \text { - ERY, e - SPI, f - TYL }
$$

Bảng 3. Đường chuẩn của các chất nhóm tetracycline và macrolide trong mẫu nước

Chất phân tích

Tetracycline

Oxytetracycline

Chlotetracycline

Erythromycin

Tylosin

Spiramycin

\section{Phương trình tuyến tính}

$Y=46,2046 x-308,0819$

$\mathrm{Y}=37,0110 \mathrm{x}-224,6509$

$Y=30,9578 x-162,8734$

$\mathrm{Y}=169,9842 \mathrm{x}+280,9997$

$\mathrm{Y}=151,5842 \mathrm{x}+88,03339$

$\mathrm{Y}=33,6860 \mathrm{x}-39,2631$
0,9994

0,9992

0,9990

0,9999

$R^{2}$

0,9996

0,9998 


\section{3. Độ thu hôi và độ lặp lại}

Xác định độ thu hồi và độ lặp lại của phương pháp bằng cách thêm chuẩn trên nền mẫu trắng ở 3 mức nồng độ 0,$1 ; 0,5 ; 1,0 \mu \mathrm{g} / \mathrm{L}$. Ở mỗi mức nông độ thực hiện lặp lại thí nghiệm 6 lân. Kết quả được thể hiện trong Bảng 4.

Bảng 4. Độ thu hôi và độ lặp lại của các chất nhóm tetracycline và macrolide $(n=6)$

\begin{tabular}{cccc}
\hline Chất phân tích & Mǘc thêm chuân $(\mu \boldsymbol{g} / \mathbf{L})$ & H \% & RS $\%$ \\
\hline Tetracycline & 0,10 & 112,30 & 5,06 \\
& 0,50 & 86,89 & 6,01 \\
Oxytetracycline & 1,0 & 96,13 & 2,44 \\
& 0,10 & 104,87 & 10,69 \\
Chlotetracycline & 0,50 & 90,12 & 3,83 \\
& 1,0 & 92,97 & 4,29 \\
Spiramycin & 0,10 & 117,70 & 11,14 \\
& 0,50 & 91,23 & 5,86 \\
& 1,0 & 100,13 & 10,80 \\
Erythromycin & 0,10 & 93,55 & 12,45 \\
& 0,50 & 100,39 & 4,00 \\
& 1,0 & 96,43 & 6,11 \\
Tylosin & 0,10 & 85,23 & 9,25 \\
& 0,50 & 101,47 & 2,20 \\
& 1,0 & 97,22 & 2,93 \\
& 0,10 & 96,08 & 4,76 \\
& 0,50 & 98,83 & 3,25 \\
\hline
\end{tabular}

Ở Hình 2 thể hiện kết quả thu được độ thu hồi đạt từ 85,23 -117,70\% nằm trong khoảng cho phép của $\mathrm{AOAC}(40$ - 120\%) ở mức thêm chuẩn 1,0 $\mu \mathrm{g} / \mathrm{L}$. Độ lặp lại RSDr từ 2,20 - 12,45\% đạt yêu cầu của $\mathrm{AOAC}(<30 \%)$ ở mức thêm chuẩn $\leq 1,0 \mu \mathrm{g} / \mathrm{L}$.
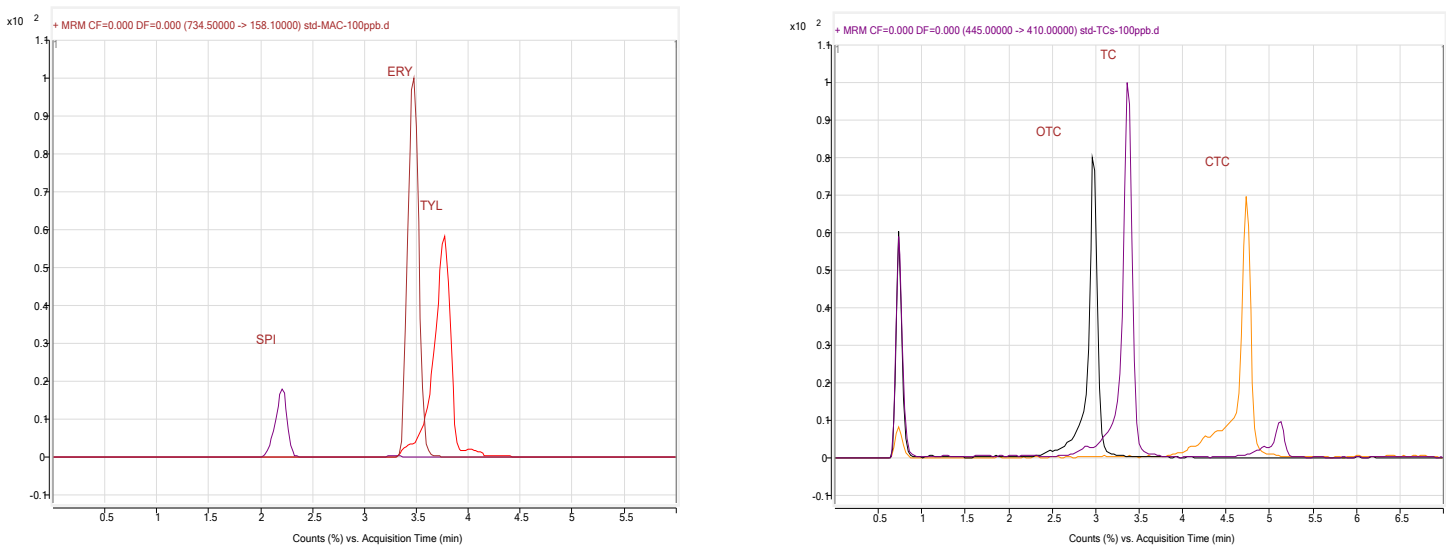

Hình 2. Sắc ký đồ mẫu thêm hỗn hợp chuân ở mức nông độ $1 \mu g / L$ đối với các chất nhóm MAC và TCs 


\section{4. Độ không đảm bảo đo của phương pháp}

Độ không đảm bảo đo được tính theo công thức thể hiện trong mục 2.5. Kết quả được thể hiện trong Bảng 5 .

Bảng 5. Độ không đảm bảo đo mở rộng của các chất phân tích nhóm tetracycline và macrolide

\begin{tabular}{cccccc}
\hline Chất phân tích & Múc nồng độ $(\mu \mathrm{g} / \mathbf{L})$ & $\boldsymbol{U}(\%)$ & $\begin{array}{c}\text { Chất } \\
\text { phân tích }\end{array}$ & Múc nồng độ $(\boldsymbol{\mu g} / \mathbf{L})$ & $\boldsymbol{U}(\%)$ \\
\hline \multirow{2}{*}{ TC } & 0,10 & 28,25 & SPI & 0,10 & 35,19 \\
& 0,50 & 30,38 & & 0,50 & 10,88 \\
& 1,0 & 10,10 & & 1,0 & 17,79 \\
OTC & 0,10 & 31,16 & ERY & 0,10 & 37,71 \\
& 0,50 & 22,11 & & 0,50 & 6,68 \\
\multirow{2}{*}{ CTC } & 1,0 & 18,01 & & 1,0 & 9,61 \\
& 0,10 & 28,98 & TYL & 0,10 & 14,90 \\
& 0,50 & 23,24 & & 0,50 & 9,07 \\
& 1,0 & 29,27 & & 1,0 & 27,34 \\
\hline
\end{tabular}

\subsection{Kết quả phân tích mẫu thực tế}

Mẫu phân tích được lấy tại bốn vị trí. Kết quả phân tích được thể hiện trong Bảng 6 . Các mẫu nước được lấy ngẫu nhiên tại tâng nước mặt trong mùa khô.

Vị trí 1: Hồ tiếp nhận nước thải bệnh viện Đại học Y Hà Nội, tọa độ $(21,0014 ; 105,8300)$ số 1 Tôn Thất Tùng, P. Khương Thượng, Q. Đống Đa, Hà Nội

Vị trí 2: Kênh tiếp nhận nước thải chợ dân sinh, tọa độ $(21,0024 ; 105,8179)$, phố Cầu Mới, P. Ngã Tư Sở, Q. Đống Đa, Hà Nội.

Vị trí 3: Trang trại Nam Hà, thôn Vân Điềm, xã Vân Hà, huyện Đông Anh, Hà Nội.

Vị trí 4: Hồ câu Đầm Nẩy, thôn Vân Điềm, xã Vân Hà, huyện Đông Anh, Hà Nội.

Bảng 6. Kết quả phân tích mẫu thực

Đơn vị: $n g / m L$

\begin{tabular}{rcccccc}
\hline Vị trí & TC & OTC & CTC & SPI & ERY & TYL \\
\hline Vị trí 1 & - & - & - & 344,83 & - & - \\
Vị trí 2 & - & 225,89 & - & - & - & - \\
Vị trí 3 & 318,63 & 358,62 & - & - & - & - \\
Vị trí 4 & - & - & - & - & - & - \\
\hline
\end{tabular}

Ghi chú: “-”: không phát hiện 
Qua kết phân tích mẫu thực cho thấy, dư lượng kháng sinh được tìm thấy tại khu vực bệnh viện, trang trại chăn nuôi và khu vực chợ thực phẩm. Tại khu vực bệnh viện hàm lượng spiramycin thuộc nhóm macrolide là 344,8 ng/L; tại trang trại chăn nuôi, hàm lượng các chất tetracycline và oxytetracycline lân lượt là 318,6 và $358,6 \mathrm{ng} / \mathrm{L}$. Trong nghiên cứu này, mặc dù mới chỉ khảo sát 04 mẫu nước thải và nước mặt đã có 03/04 mẫu phát hiện thấy dư lượng kháng sinh, đặc biệt có 01 mẫu chứa 02 loại kháng sinh. Điều này bước đầu cho thấy mức độ tôn dư kháng sinh trong nước mặt và nước thải ở Hà Nội là khá phổ biến.

Theo tác giả Hoa và cộng sự [11], các chất nhóm macrolide được tìm thấy trong hệ thống kênh hoặc các sông tiếp nhận nước thải ở Hà Nội như spiramycin, oleandomycin, azithromycin với nồng độ lần lượt là 90,8, 134, 621 ng/L. Các chất nhóm tetracycline được phát hiện trong hệ thống thoát nước đô thị, kênh thành phố, kênh ngoại ô và sông nhưng với tần suất ít hơn. Trong hệ thống thoát nước đô thị, TC và OTC chỉ được phát hiện trong 2 mẫu ở nông độ $258 \mathrm{ng} / \mathrm{L}$ (tại Hà Nội) và 316 ng/L (tại Cần Thơ), trong khi đó OTC được phát hiện ở kênh trong thành phố, kênh ngoại ô và sông với nồng độ nhỏ hơn 5,226 và $7 \mathrm{ng} / \mathrm{L}$. Như vậy, hàm lượng kháng sinh thu được từ các mẫu nước thực tế có giá trị tương đương với các nghiên cứu của các tác giả khác, đều gây nguy hại cho hệ sinh thái ở khoảng nồng độ ng/L.

\section{KẾT LUẠN}

Phương pháp xác định các chất nhóm tetracycline và macrolide trong môi trường nước được thực hiện trong nghiên cứu là đáng tin cậy với hệ số tương quan tuyến tính $\mathrm{R}^{2} \mathrm{cao}(>0,9990)$, độ thu hôi nằm trong khoảng cho phép của $\mathrm{AOAC}$ (nằm trong khoảng 40 - 120\%) và độ lặp lại $\mathrm{RSDr}<30 \%$ ở mức thêm chuẩn $1,0 \mu \mathrm{g} / \mathrm{L}$. Giới hạn phát hiện của phương pháp (LOD) là 0,03 $\mu \mathrm{g} / \mathrm{L}$, giới hạn định lượng của phương pháp (LOQ) là $0,10 \mu \mathrm{g} / \mathrm{L}$. Độ không đảm bảo đo của phương pháp $(\mathrm{U})$ từ 9,61 -37,71\%. Kết quả phân tích mẫu thực tế cho thấy hàm lượng dư lượng kháng sinh được tìm thấy trong nước thải khu vực bệnh viện, trang trại chăn nuôi và khu vực chợ thực phẩm nằm trong khoảng 225,9 - 358,6 ng/L. Kết quả phân tích 04 mẫu khảo sát thì có 03/04 mẫu phát hiện có dư lượng kháng sinh, đặc biệt có 01 mẫu chứa 02 loại kháng sinh với hàm lượng từ 225,9 - 358,6 ng/L. Hàm lượng kháng sinh trong các mẫu nghiên cứu tương đương với các kết quả nghiên cứu của các tác giả trước đây.

\section{TÀI LIỆ THAM KHẢO}

[1]. Suzuki, S., \& Hoa, P. T. P., "Distribution of quinolones, sulfonamides, tetracyclines in aquatic environment and antibiotic resistance in Indochina", Frontiers in Microbiology, vol. 3, no. 67, 2012.

[2]. Liu, X., Guo, X., Liu, Y., Lu, S., Xi, B., Zhang, J., \& Bi, B., "A review on removing antibiotics and antibiotic resistance genes from wastewater by constructed wetlands: performance and microbial response”, Environmental Pollution, vol. 254, 112996, 2019.

[3]. Bộ Nông nghiệp, "Ban hành danh mục thuốc, hóa chất, kháng sinh cấm sử dụng, hạn chế sử dụng”, Phụ lục 3/TT15-2009/BNN, 2009.

[4]. Binh, V. N., Dang, N., Anh, N. T. K., \& Thai, P. K., "Antibiotics in the aquatic environment of Vietnam: sources, concentrations, risk and control strategy", Chemosphere, vol. 197, pp. 438-450, 2018.

[5]. Kümmerer, K, “Antibiotics in the aquatic environment e a review e Part II", Chemosphere, vol. 75, pp. 435-441, 2009. 
[6]. Le, T.X., Munekage, Y., Kato, S., "Antibiotic resistance in bacteria from shrimp farming in mangrove areas", Science of the Total Environment, vol. 349, pp. 95-105, 2005.

[7]. Kim, Y., Choi, K., Jung, J., Park, S., Kim, P.G., Park, J., "Aquatic toxicity ofacetaminophen, carbamazepine, cimetidine, diltiazem and six majorsulfonamides, and their potential ecological risks in Korea", Environment International, vol. 33, pp. 370-375, 2007.

[8]. Fatta-Kassinos, D., Meric, S., \& Nikolaou, A., "Pharmaceutical residues in environmental waters and wastewater: current state of knowledge and future research", Analytical and bioanalytical chemistry, vol. 399, no. 1, pp. 251-275, 2011.

[9]. Lin, A. Y. C., Yu, T. H., \& Lin, C. F., "Pharmaceutical contamination in residential, industrial, and agricultural waste streams: risk to aqueous environments in Taiwan", Chemosphere, vol. 74, no. 1, pp. 131-141, 2008.

[10]. Viện Kiểm nghiệm an toàn vệ sinh thực phẩm Quốc gia, Thẩm định phương pháp trong phân tích hóa học và vi sinh vật. Hà Nội: Nhà xuất bản Khoa học và Kỹ thuật, 2010.

[11]. Hoa, P.T.P., Managaki, S., Nakada, N., Takada, H., Shimizu, A., Anh, D.H., Viet, P.H., Suzuki, S., "Antibiotic contamination and occurrence of antibiotic-resistant bacteria in aquatic environments of northern Vietnam", Science of the Total Environment, vol. 409, pp. 2894-2901, 2011.

\title{
Determination of macrolide and tetracyclins group in water by liquid chromatography tandem mass spectrometry (LC-MS/MS)
}

\author{
Le Van Trong ${ }^{1,2}$, Nguyen Thi Thanh Hang ${ }^{1}$, Do Quang Huy ${ }^{2}$, Nguyen Manh Khai ${ }^{2}$ \\ ${ }^{1}$ National Center for Food Analysis and Assessment - Food Industries Research Institute \\ ${ }^{2}$ Faculty of Environmental Sciences, University of Sciences, Vietnam Nationnal University, Hanoi.
}

\section{Abstract}

Antibiotics are contaminants at low concentrations and found in water with the range of $\mathrm{ng} / \mathrm{L}$. Determination of antibiotics at trace concentrations requires modern and high accuracy equipment. Liquid chromatography mass tandem spectrometry (LC-MS/MS) able to determine contaminants at ppt and ppb levels, which is suitable for quantification of the macrolide and tetracycline group in water. The Analytical method using Agilent Triple Quard 6460 LC-MS/MS system with positive ion mode. Agilent XDB C18 column $(1.8 \mu \mathrm{m} \times 2.1 \times 100 \mathrm{~mm})$ and Agilent Eclipse SDB C18 pre-column $(2.1 \times 5 \mathrm{~mm} \times 1.8 \mu \mathrm{m})$ were used. Mobile phase was acetonitrile and $\mathrm{HCOOH} 0.1 \%$. Samples were cleaned with Oasis PRiME HLB 3cc SPE column (150 mg). The method was evaluated based on specificity, recovery, repeatability and estimation of the uncertainty. The method detection limit (MDL) for the analytes is $0.03 \mu \mathrm{g} / \mathrm{L}$. Recovery ranges from $85.23 \%$ to $117.70 \%$; repeatability (RSDr) is between $2.20 \%$ and $12.45 \%$.

Keywords: antibiotics, macrolides, tetracyclines, LC-MS/MS. 